\title{
Trials for preparation and evaluation of a combined inactivated reassorted H5N1 and Escherichia coli 0157 vaccine in poultry
}

\author{
Marwa Fathy El Sayed(D, Reem A. Soliman (D), Heba Mohamed Ghanem(D, Marwa M.S. Khedr(D), Gina M. Mohamed(D) \\ and Mounir Mohamed Diab El Safty \\ Central Laboratory for Evaluation of Veterinary Biologics, Agricultural Research Center, Giza, Egypt. \\ Corresponding author: Gina M. Mohamed, e-mail: gina_mohammed@msn.com \\ Co-authors: MFE: omsagda_2013@yahoo.com, RAS: janajanamostafa@gmail.com, HMG: ahmhy20@hotmail.com, \\ MMSK: magdymarwa375@yahoo.com,MMDE: melsafty_hobs@yahoo.com \\ Received: 19-12-2020, Accepted: 06-05-2021, Published online: 28-06-2021
}

doi: www.doi.org/10.14202/vetworld.2021.1677-1681 How to cite this article: El Sayed MF, Soliman RA, Ghanem HM, Khedr MMS, Mohamed GM, El Safty MMD (2021) Trials for preparation and evaluation of a combined inactivated reassorted H5N1 and Escherichia coli O157 vaccine in poultry, Veterinary World, 14(6): 1677-1681.

\begin{abstract}
Background and Aim: Avian influenza (AI), which is one of the major respiratory diseases of poultry, and Escherichia coli (E. coli) have caused major economic losses around the world, including in Egypt. Therefore, in this study, we aimed to produce a vaccine from E. coli $\mathrm{O} 157$ and AI H5N1 formulated with Montanide ISA70 for the protection of poultry against both diseases.

Materials and Methods: We divided one hundred 3-week-old chicks into four groups: Group 1 was vaccinated with prepared inactivated AI H5N1 formulated with Montanide ISA70, Group 2 was vaccinated with inactivated $E$. coli formulated with Montanide ISA70, Group 3 was vaccinated with combined E. coli and AI H5N1 formulated with Montanide ISA70, and Group 4 was an unvaccinated control group. We measured the immune response using the HI (hemagglutination inhibition) test, enzyme-linked immunosorbent assay (ELISA), and the challenge test.

Results: We found the three vaccines to be safe and sterile during all periods of examination and observation. The HI test showed that Group 1 exhibited specific antibody titers of $2.3 \log _{2}, 4.3 \log _{2}, 7.5 \log _{2}, 7.8 \log _{2}, 8 \log _{2}$, and $8.1 \log _{2}$ from week 2 to week 7 , respectively, post-vaccination. Group 3 exhibited antibody titers of $3.3 \log _{2}, 5.8 \log _{2}, 7.8 \log _{2}, 8 \log _{2}, 8.3 \log _{2}$, and 8.3 $\log _{2}$ from week 2 to week 7 , respectively, post-vaccination. The immune response in both groups reached a high titer at week 6. The combined inactivated $E$. coli and AI H5N1 vaccine generated a higher immune response than the inactivated AI H5N1 vaccine, and a significant difference exists between the two groups. For Groups 2 and 3, the ELISA antibody titer exhibited its lowest value, 1996.5 and 2036.7, respectively, at week 1 post-vaccination; whereas, both groups exhibited the highest titers, 2227.7 (for Group 2) and 2287.3 (for Group 3), in week 3 post-booster. The ELISA for the combined inactivated E. coli and AI H5N1 vaccine had a higher titer than did the inactivated $E$. coli vaccine, and a significant difference exists between the two groups. Moreover, the protection rate was higher in Group 3, with 100\% for E. coli and 90\% for the AI H5N1 vaccine.
\end{abstract}

Conclusion: Our findings demonstrate that producing a combined vaccine using E. coli and AI H5N1 formulated with Montanide ISA70 is recommended for protection against both diseases.

Keywords: avian influenza (H5N1), Escherichia coli O157, enzyme-linked immunosorbent assay, hemagglutination inhibition test, Montanide ISA70.

\section{Introduction}

Avian influenza (AI) is a poultry disease with the potential to cause major epidemics resulting in significant economic losses. AI is an economically important respiratory disease for poultry in Egypt and across the globe. AI viruses belong to type A of the Orthomyxoviridae family, and 18 hemagglutinins (H1-H18) and 11 neuraminidase subtypes (N1-N11) have been reported.

One possible explanation for such a high mortality rate and great financial losses can be a mixed infection with other respiratory pathogens. A member of Enterobacteriaceae family, pathogenic Escherichia coli

Copyright: El Sayed, et al. Open Access. This article is distributed under the terms of the Creative Commons Attribution 4.0 International License (http://creativecommons.org/licenses/ by/4.0/), which permits unrestricted use, distribution, and reproduction in any medium, provided you give appropriate credit to the original author(s) and the source, provide a link to the Creative Commons license, and indicate if changes were made. The Creative Commons Public Domain Dedication waiver (http:// creativecommons.org/publicdomain/zero/1.0/) applies to the data made available in this article, unless otherwise stated.
(E. coli) $\mathrm{O} 157$ is a factor that can affect the pathogenicity of the AI H5N1 virus [1]. This bacterium is categorized on the basis of its somatic and flagellar antigens. Colisepticemia or aerosol disease is the most important disease in poultry caused by avian pathogenic E. coli (APEC) strains resulting in high mortality, and it is the most common bacterial infection in poultry. This infection usually occurs among birds 2-12 weeks of age, with the majority of the cases occurring among birds 4-9 weeks of age, with mortality rates as high as $20 \%$.

In broilers, colibacillosis is often considered secondary to other pathogens and unfavorable environmental conditions such as the Newcastle disease virus, the infectious bronchitis virus, and the AI virus [2]. The combination of bacterial and viral vaccines containing multiple antigens has many benefits for manufacturers, as it reduces production costs; for administrators, as it saves time and efforts as well as simplifies the immunization schedule; and for the animals, as it minimizes the stress of multiple vaccinations [3]. 
A recent study in Egypt by Marwa et al. [4] who isolated and identified a new strain of $E$. coli $\mathrm{O} 175$, which caused severe economic losses in several poultry farms in Egypt along with AI, and by Azza et al. [5], who detected the pathogenicity of E. coli serogroup $\mathrm{O} 157$ in broiler chicks, indicating a threat not only to the birds but also to public health. Therefore, we have focused our study on this topic.

Therefore, in this study, we aimed to produce a vaccine from E. coli $\mathrm{O} 157$ and $\mathrm{AI} \mathrm{H} 5 \mathrm{~N} 1$ formulated with Montanide ISA70 for the protection of poultry against both diseases.

\section{Materials and Methods}

\section{Ethical approval}

The study was approved by Institutional Animal Care and Use Committee at Central Laboratory for Evaluation of Veterinary Biologics, Cairo, Giza, Egypt.

\section{Study period and location}

The study was conducted in March 2020 at Central Laboratory for Evaluation of Veterinary Biologics, Cairo, Giza, Egypt.

\section{Strains used}

E. coli serotype O157, which was isolated locally [4], was inoculated on MacConkey agar medium and incubated at $37^{\circ} \mathrm{C}$ for $24 \mathrm{~h}$. The strain was identified biochemically using the API 20E identification system following the procedures in the Biomerieux kit manual. The AI virus (HPAI/chicken/Egypt/D10552B/2015 H5N1), obtained from the National Research Center, Giza, Egypt, was egg adapted with titer.

\section{Chickens}

A total of one hundred and sixty 3-week-old specific pathogen-free (SPF) chicks were obtained from Koom-Osheim Farm in the Faiyum Governorate. The chickens were fed ad libitum without any antibacterial or anticoccidial components in their feed.

\section{Vaccine preparation}

E. coli $\mathrm{O} 157$ was grown separately on brain heart agar and incubated at $37^{\circ} \mathrm{C}$ for $24 \mathrm{~h}$. The colonies were collected using normal saline and mixed, and the bacterial suspension was adjusted to be $1 \times 10^{9}$ $\mathrm{CFU} / 0.5 \mathrm{~mL}$ (vaccinal dose). The bacteria were inactivated by adding $0.5 \%$ formalin with agitation, then Montanide ISA70 (SEPPIC ${ }^{\circledR}$, France) was mixed with one part of the bacterial suspension in a ratio of 70:30 (w/w) (adjuvant: antigen) [6].

Propagation and titration of AI H5N1, which was isolated locally, were done in embryonated chicken egg SPF that was 9-10 days old, according to Chaffer et al. [6]. Its titer was $10^{9} \mathrm{EID} 50 / \mathrm{mL}$. Inactivation of the AI virus was carried out using binary ethylenimine $(0.1 \mathrm{M})$, with a final concentration of $0.01 \mathrm{M}$. Inactivation and its testing were done according to Sarachai et al. [7].

A combined vaccine of $E$. coli and AI H5N1 was prepared in water emulsion by mixing equal volumes of the inactivated $E$. coli antigenic phase and inactivated $\mathrm{AI}$ antigenic phase to form an aqueous phase and then was mixed with Montanide ISA70 in a ratio of 70:30 (w/w) (adjuvant: antigen).

\section{Experimental design}

A total of one hundred and sixty 3-week-old SPF chicks were divided into four groups, with 40 in each:

- For Group 1, chicks were vaccinated with inactivated AI H5N1 formulated with Montanide ISA70 in a dose of $0.5 \mathrm{~mL} \mathrm{~S} / \mathrm{C}\left(1 \times 10^{9} \mathrm{CFU} /\right.$ dose $)$

- For Group 2, chicks were vaccinated with inactivated $E$. coli formulated with Montanide ISA70 using the same dose as Group 1

- For Group 3, chicks were vaccinated with combined inactivated E. coli and AI H5N1 formulated with Montanide ISA70 in a dose of $0.5 \mathrm{~mL} \mathrm{S/C}$

- For Group 4, chicks were injected with $0.5 \mathrm{~mL}$ $\mathrm{S} / \mathrm{C}$ normal saline; this was the control group.

Birds in Groups 2 and 3 were given booster dose of the vaccine (E. coli only) through the same route and in the same dose, 3 weeks after the first immunization. Serum samples were obtained regularly before immunization, weekly after each vaccination, and post-challenge for 2 weeks (once/week). These serum samples were then pooled and stored at $-20^{\circ} \mathrm{C}$ until use during follow-up for the induced antibodies.

\section{Quality control testing of the prepared experimental vaccines}

The vaccines were tested for sterility and safety following the standard international protocol [8] before usage in the field trial.

\section{Determination of an immune response to the pre- pared experimental vaccines}

The enzyme-linked immunosorbent assay (ELISA) test was performed on the serum sample of tested chickens according to the method described by Voller et al. [9] and Briggs and Skeels [10], for evaluation of immune response against $E$. coli in Groups 2 and 3. The results were calculated according to the following formula:

Sample mean

$$
\begin{aligned}
\mathrm{S} / \mathrm{P}(\text { sample / positive })= & \frac{- \text { Negative control }}{\text { Positive control }} \\
& - \text { Negative control }
\end{aligned}
$$

- $\quad \log 10$ titer $=1.09(\log 10 \mathrm{~S} / \mathrm{P})+3.63$

- Titer = Antilog 10.

The HI (hemagglutination inhibition) test was carried out [8] for the evaluation of immune response in Groups 1 and 3 against AI.

For the challenge tests for the virulent $E$. coli strains, 3 weeks after the booster dose, vaccinated chickens (20 birds/flock) from Groups 2 and 3 as well as the non-vaccinated birds were injected in the thigh region with $0.2 \mathrm{~mL}$ (containing $10^{7} \mathrm{CFU}$ ) of E. coli serotype $\mathrm{O} 157$ and monitored for clinical signs. Mortality was recorded for 7 days after the challenge according to the method described by Chaffer et al. [6].

For the challenge tests for the AI H5N1 strain, 20 vaccinated chickens from Groups 1 and 3, as well as 10 non-vaccinated birds, were challenged by inoculation 
of $0.1 \mathrm{~mL}$ of AI H5N1 (106 EID50) strain through the intranasal route 4 weeks after first and a booster dose of vaccination. Then, tracheal and cloacal swabs were collected on days $1,3,5,7$, and 10 post-challenge to check for virus shedding. Mortality was recorded to calculate the percentage of protection [11].

\section{Statistical analysis}

We analyzed the results of the HI tests (Table-1) and ELISA tests (Table-2) and compared the parametrical correlations using Student's t-test [12]. Significance level was set at $\mathrm{p}>0.05$

\section{Results}

We found all three vaccines to be safe and sterile during all periods of examination and observation. The humoral immune response against the reassorted AI H5N1 measured by the HI test is illustrated in Table-1, while the immune response against E. coli serotype $\mathrm{O} 157$ measured by ELISA is illustrated in Table-2 and Figure-1.

\section{HI tests}

The HI tests for the vaccinated chickens showed that Group 1 exhibited specific antibody titers of 2.3 $\log _{2}, 4.3 \log _{2}, 7.5 \log _{2}, 7.8 \log _{2}, 8 \log _{2}$, and $8.1 \log _{2}$ from week 2 to week 7 , respectively, post-vaccination (Table-1). Group 3 exhibited antibody titers of $3.3 \log _{2}$, $5.8 \log _{2}, 7.8 \log _{2}, 8 \log _{2}, 8.3 \log _{2}$, and $8.3 \log _{2}$ from week 2 to week 7 , respectively, post-vaccination. The

Table-1: Mean AI-HI antibody titer in vaccinated chickens with inactivated monovalent AI vaccine (Group 1) and bivalent ( $E$. coli and AI) vaccine (Group 3 ).

\begin{tabular}{lccc}
\hline Weeks & \multicolumn{3}{c}{ Mean AI-HI antibody titers* } \\
\cline { 2 - 4 } & Group 1 & Group 3* & Group 4 \\
\hline $1^{\text {st }}$ & 0 & 0 & 0 \\
$2^{\text {nd }}$ & 2.3 & 3.3 & 0 \\
$3^{\text {rd }}$ & 4.3 & 5.8 & 0 \\
$4^{\text {th }}$ & 7.5 & 7.8 & 0 \\
$5^{\text {th }}$ & 8.5 & 9 & 0 \\
$6^{\text {th }}$ & 9.6 & 10.8 & 0 \\
$7^{\text {th }}$ & 10.7 & 11 & 0 \\
\hline
\end{tabular}

Group 1: Vaccinated with inactivated AI vaccine formulated with Montanide ISA70. Group 3: Vaccinated with combined inactivated $E$. coli + AI vaccine formulated with Montanide ISA70. Group 4: Control group. *Antibody titers were expressed as log2. *Significant at $p>0.05$. $\mathrm{AI}=$ Avian influenza, E. coli=Escherichia coli immune response in both groups reached a high titer at week 6 . Thus, the combined inactivated $E$. coli and AI vaccine gives a higher immune response than the inactivated AI vaccine, with a significant $(\mathrm{p}>0.05)$ difference between the two groups.

\section{ELISA}

In the ELISA tests, antibody titer against $E$. coli O157 in vaccinated chickens is shown in Table-2 and Figure-1. In Groups 2 and 3, the ELISA antibody titer exhibited the lowest values-1996.5 and 2036.7, respectively at 1 week post-vaccination; whereas, both groups exhibited the highest titer-2227.7 for Group 2 and 2287.3 for Group 3-at 3 week after the booster dose (Table-2 and Figure-1). Thus, the combined inactivated $E$. coli and AI vaccine gave a higher titer than the inactivated $E$. coli vaccine, with a significant $(\mathrm{p}>0.05)$ difference between the two groups.

\section{Challenge tests}

In the AI challenge tests, Group 1 had $80 \%$ protection rate and Group 3 had $90 \%$ protection rate (Table-3). The unvaccinated control Group 4 was unable to withstand the virulent challenge virus, with $0 \%$ protection. In E. coli challenge tests, Group 2 had $90 \%$ protection rate and Group 3 had $100 \%$ protection rate (Table-4). Control Group 4 had $0 \%$ protection.

\section{Discussion}

Bacteria such as E. coli and viral diseases like AI represent major problems in the poultry industry. APEC causes a systemic disease that is highly lethal in both broiler and layer chickens and is the leading cause of the $1^{\text {st }}$ week mortality in layers [13]. AI H5N1 is a highly contagious viral disease, which affects several species of birds, and is caused by influenza virus type A, which is a member of the family Orthomyxoviridae [14].

Vaccination is the cornerstone in controlling and eradicating such diseases. One previous study has shown that inactivated vaccines are capable of increasing antibody response, which protect the birds from death and against a decline in egg production [15]. Vaccine quality improvement is also necessary. An effective vaccine needs not only a good antigen but also a preferable adjuvant to enhance both cellular and humoral immunities. In addition, reducing post-vaccination side effects using mineral oil emulsion vaccine potentiates the antibody

Table-2: ELISA antibody titer against E. coli O157 in vaccinated chicken.

\begin{tabular}{|c|c|c|c|c|c|c|c|c|c|c|c|}
\hline \multirow[t]{3}{*}{ Groups } & \multicolumn{11}{|c|}{ ELISA antibody titer } \\
\hline & \multirow[t]{2}{*}{$\begin{array}{c}\text { Pre- } \\
\text { vaccination }\end{array}$} & \multicolumn{3}{|c|}{$\begin{array}{c}\text { Weeks } \\
\text { post-vaccination }\end{array}$} & \multirow[t]{2}{*}{ Booster } & \multicolumn{3}{|c|}{$\begin{array}{c}\text { Weeks } \\
\text { post-boostering }\end{array}$} & \multirow[t]{2}{*}{ Challenge\# } & \multicolumn{2}{|c|}{$\begin{array}{c}\text { Weeks } \\
\text { post-challenge }\end{array}$} \\
\hline & & 1 & 2 & 3 & & 1 & 2 & 3 & & 1 & 2 \\
\hline Group (2) & 93 & 1996.5 & 2151.6 & 2172.2 & & 2025.8 & 2192.5 & 2227.7 & & 2100.5 & 2254.1 \\
\hline Group (3)* & 110 & 2036.7 & 2046.8 & 2166.1 & & 2171.8 & 2202.1 & 2287.3 & & 2061.2 & 2469.3 \\
\hline Control & 110 & 193 & 120 & 244 & & 157 & 166 & 244 & & 120 & 106 \\
\hline
\end{tabular}

Group (2): Vaccinated with inactivated E. coli vaccine formulated with Montanide ISA70. Group (3): Vaccinated with combined inactivated E. coli +AI vaccine formulated with Montanide ISA70. \#Challenge with virulent E. coli (O157) strain. *Significant at p>0.05. AI=Avian influenza, E. coli=Escherichia coli, ELISA=Enzyme-linked immunosorbent assay 


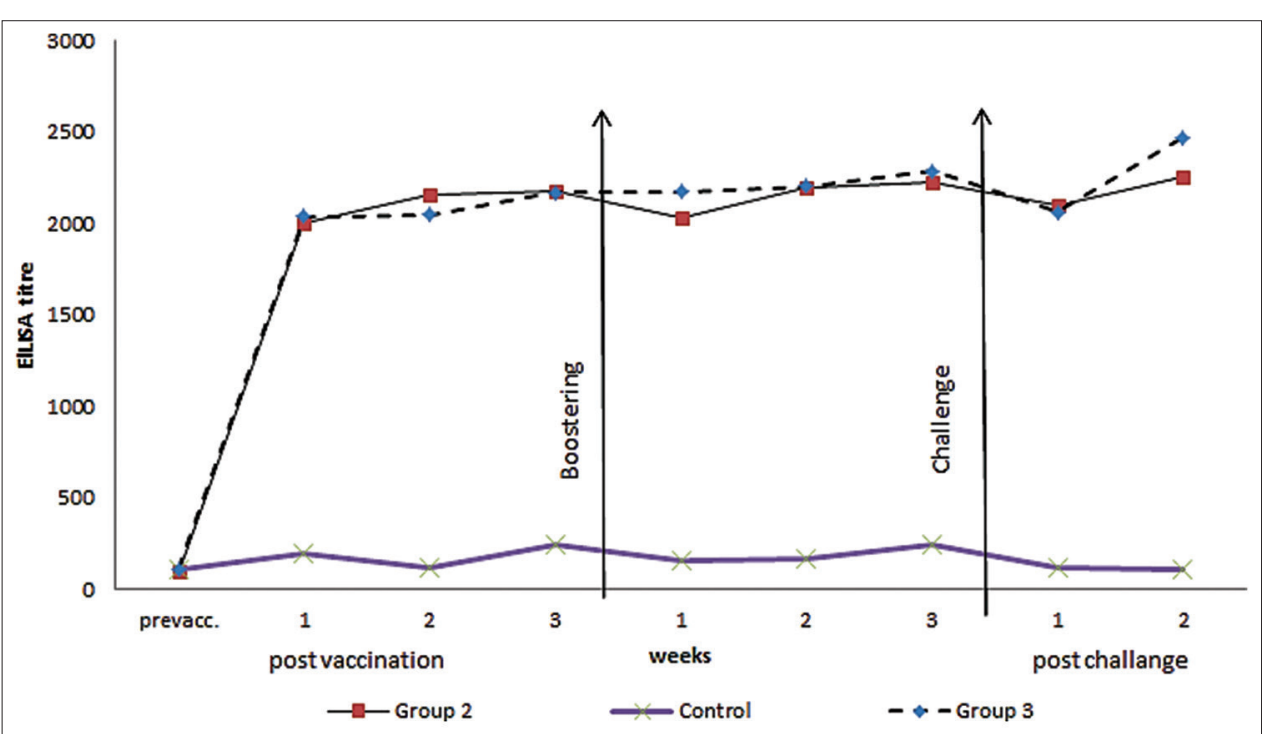

Figure-1: Enzyme-linked immunosorbent assay antibody titer against Escherichia coli 0157 in vaccinated chicken.

Table-3: Results of challenge test among chickens vaccinated with inactivated AI vaccine and combined inactivated E. coli and AI vaccine against serotype (H5N1).

\begin{tabular}{lcccccccccccccc}
\hline $\begin{array}{l}\text { Groups of } \\
\text { chicken }\end{array}$ & $\begin{array}{c}\text { Total no. of } \\
\text { challenged birds }\end{array}$ & \multicolumn{1}{c}{ chays post-challenge } & \multicolumn{4}{c}{$\begin{array}{c}\text { Total } \\
\text { death }\end{array}$} & $\begin{array}{c}\text { Protection Reisolation } \\
\text { rate }\end{array}$ \\
\cline { 2 - 14 } & & $\mathbf{1}$ & $\mathbf{2}$ & $\mathbf{3}$ & $\mathbf{4}$ & $\mathbf{5}$ & $\mathbf{6}$ & $\mathbf{7}$ & $\mathbf{8}$ & $\mathbf{9}$ & $\mathbf{1 0}$ & & \\
\hline Group (1) & 20 & - & 1 & 3 & & & & & & & $4 / 20$ & $80 \%$ & $-\mathrm{ve}$ \\
Group (3) & 20 & - & - & 1 & 1 & & & & & & $2 / 20$ & $90 \%$ & $-\mathrm{ve}$ \\
Control & 10 & 3 & 2 & 5 & & & & & & & $10 / 10$ & $0 \%$ & $+\mathrm{ve}$ \\
\hline
\end{tabular}

$\mathrm{AI}=$ Avian influenza, $E$. coli=Escherichia coli

Table-4: Results of challenge test among chickens vaccinated with inactivated $E$. coli vaccine and combined inactivated $E$. coli and AI vaccine against $E$. coli serotype 0157 .

\begin{tabular}{|c|c|c|c|c|c|c|c|c|c|c|c|c|c|c|}
\hline \multirow{2}{*}{$\begin{array}{l}\text { Groups of } \\
\text { chicken }\end{array}$} & \multirow{2}{*}{$\begin{array}{c}\text { Total no. of } \\
\text { challenged birds }\end{array}$} & \multicolumn{10}{|c|}{ Days post-challenge } & \multirow{2}{*}{$\begin{array}{l}\text { Total } \\
\text { death }\end{array}$} & \multirow{2}{*}{$\begin{array}{l}\text { Protection } \\
\text { rate }\end{array}$} & \multirow[t]{2}{*}{ Reisolation } \\
\hline & & 1 & 2 & 3 & 4 & 5 & 6 & 7 & 8 & 9 & 10 & & & \\
\hline Group (2) & 20 & - & 1 & 1 & & & & & & & & $2 / 20$ & $90 \%$ & $-v e$ \\
\hline Group (3) & 20 & - & - & & 1 & & & & & & & $0 / 20$ & $100 \%$ & $-v e$ \\
\hline Control & 10 & 3 & 2 & 5 & & & & & & & & $10 / 10$ & $0 \%$ & + ve \\
\hline
\end{tabular}

$\mathrm{AI}=$ Avian influenza, $E$. coli=Escherichia coli

response and prolongs the duration of immunity [16]. Montanide ISA70 oil adjuvant, which is characterized by low viscosity and easy injectability, also enhances the cellular and humoral immunities, increasing the protection limit of the vaccine [17].

The vaccines tested by us were found to be safe, protecting the chickens without any untoward reactions. Using Montanide ISA70 provided a high immune response and protection rate in the three vaccines; the combined bivalent vaccine gave higher titer and protection than the monovalent vaccine. This finding agrees with the study of El-Sayed et al. [17] who revealed that Montanide ISA206 or ISA70 oil adjuvants confer good, long-lasting protection. Our results of the ELISA tests were in agreement with those of Mohammed et al. [18] who found that the ELISA titer against $E$. coli for an inactivated vaccine with Montanide ISA70 was higher than inactivated vaccine with aluminum hydroxide gel as an adjuvant.

In our experimental trials, the chickens vaccinated with combined inactivated $E$. coli and AI gave a higher immune response at week 7 than those vaccinated with the inactivated $E$. coli. In an investigation of $\mathrm{HI}$ and ELISA tests of the sera of chickens vaccinated with combined AI (H9N2) and fowl cholera (FC), the study by Salama et al. [19] indicated similar results until week 6 post-vaccination for $\mathrm{FC}$ using Montanide ISA206. In addition, Ghanem et al. [20] have stated that using Montanide ISA70 as an adjuvant in preparation of bivalent combined vaccine (AI + FC), monovalent AI vaccine and monovalent FC vaccine gave better post-vaccine reaction and higher immune response than using white oil adjuvant.

The two vaccines in Groups 1-3 had protection rates of $80-100 \%$. These results agree with those of Salama et al. [19] who found protection levels of 80-93.3\% against Pasteurella multocida and 96.6\% against AI virus after challenging with the used virulent strains after the single and booster doses, respectively. Moreover, Ghanem et al. [20] found a high degree of protection for layers and chicks with a vaccine prepared from trivalent E. coli (serotypes O1, 
O2, and O78) and an inactivated Newcastle disease. Further, Erganis et al. [21] have declared that both the heat and formalin-inactivated aluminum precipitated vaccines prepared with the virulent $E$. coli isolates were effective in protecting chickens of different ages against various forms of avian colibacillosis.

\section{Conclusion}

The chickens in our study, which were vaccinated with inactivated E. coli, AI H5N1, and both combined, exhibited a high immune response and rate of protection, thereby suggesting the development of strong and long-lasting immunity. Thus, we concluded that producing a vaccine from E. coli and AI H5N1 formulated with Montanide ISA70 can protect against both $E$. coli and AI, helping to mitigate the economic impact of these diseases.

\section{Authors' Contributions}

All authors designed and planned this research work. MMSK and HMG: Identified the strains. RAS and GMM: Prepared the vaccine. MFE and RAS: Experimental design and challenge test were carried out. MFE, RAS, HMG, MMSK, and GMM: Determination of immune response. MMDE: Statistical analysis. All authors contributed equally in preparation and revision of the manuscript and collection of scientific papers related to the subject of this research. All authors read and approved the final manuscript.

\section{Acknowledgments}

The materials used in this study were supplied by Central Laboratory for Evaluation of Veterinary Biologics, Egypt. The authors are thankful to all the technical staff of Microbiology, Virology Department of Central Laboratory for Evaluation of Veterinary Biologics for their contribution in the practical part of this study.

\section{Competing Interests}

The authors declare that they have no competing interests.

\section{Publisher's Note}

Veterinary World remains neutral with regard to jurisdictional claims in published institutional affiliation.

\section{References}

1. Jaleel, S., Younus, M., Idrees, A., Arshad, M., Khan, A.U., Ehtisham-Ul-Haque, S., Zaheer, M.I., Tanweer, M., Towakal, F., Tipu, M.Y.M., Sohail, M.L. and Umar, S. (2017) Pathological alterations in the respiratory system during co-infection with low pathogenic avian influenza virus (H9N2) and Escherichia coli in broiler chickens. J. Vet. Res., 61(3): 253-258.

2. Barnes, H.J. and Gross, W.B. (1997) Colibacillosis. In: Calnek, B.W., editor. Diseases of Poultry. $10^{\text {th }}$ ed. Ames, Iowa State University Press. p131-141.

3. Orabi, A., Hussein, A., Saleh, A.A., El-Magd, M.A. and
Munir, M. (2017) Evolutionary insights into the fusion protein of Newcastle disease virus isolated from vaccinated chickens in 2016 in Egypt. Arch. Virol., 162(10): 3069-3079.

4. Marwa, D., Abdelaty, M.F. and Abotaleb, M.M. (2019) Isolation and identification of E-coli from infected cases from broilers farms in 2019. Int. J. Agric. Biol. Sci., 3(12): 100-109.

5. Azza, A., AL Hussien, M., El-Shaymaa A.I. and Abd El Mawgoud, A.I. (2018) Pathogenicity of Escherichia coli O157 in commercial broiler chickens. Beni-Suef Univ. J. Basic Appl. Sci., 7(4): 620-625.

6. Chaffer, M., Schwartsburd, B. and Heller, E. D. (1997) Vaccination of turkey poults against pathogenic Escherichia coli. Avian Pathol., 26(2): 377-390.

7. Sarachai, C., Sasipreeyajan, J. and Chansiripornchai, N. (2014) Characterization of avian influenza H5N1 virosome. Pak. Vet. J., 34(2): 201-204.

8. OIE. (2019) Manual of Standard of Diagnostic Tests and Vaccines for Terrestrial Animals Safety Test. Ch. 2.3.4. Avian Influenza, OIE, Paris. p446.

9. Voller, A., Bidwell, D.E. and Bartlett, A. (1976) Enzyme immunoassay in diagnostic medicine theory and practice. Bull. World Health. Organ., 53(1): 55-65.

10. Briggs, D.J. and Skeels, J.K. (1984) An enzyme-linked immunosorbent assay for detecting antibodies to Pasteurella multocida in chickens. Avian Dis., 28(1): 208-215.

11. Kwon, J.S.P., Lee, H.J., Lee, D.H., Lee, Y.J., Mo, I.P., Nahm, S.S., Kim, M.J., Lee, J.B., Park, S.Y., Choi, I.S. and Song, C.S. (2008) Immune responses and pathogenesis in immunocompromised chickens in response to infection with the H9N2 low pathogenic avian influenza virus. Virol. Res., 133(2): 187-194.

12. Snedecor, G.W. and Cochran, W.G. (1980) Statistical Methods. $7^{\text {th }}$ ed. Iowa State University, Ames.

13. Kim, Y.B., Yoon, M.Y., Ha, J.S., Seo, K.W., Noh, E.B., Son, S.H. and Lee, Y.J. (2020) Molecular characterization of avian pathogenic Escherichia coli from broiler chickens with colibacillosis. Poult. Sci., 99(2): 1088-1095.

14. Mosleh, N., Dadras, H., Asasi, K., Taebipour, M.J., Tohidifar, S.S. and Farjanikish, G. (2017) Evaluation of the timing of the Escherichia coli co-infection on pathogenicity of H9N2 avian influenza virus in broiler chickens. Iran. J. Vet. Res., 18(2): 86-91.

15. Capua, I. and Alexander, D.J. (2008) Avian influenza vaccine and vaccination in birds. Vaccine, 26(4): D70-D73.

16. Gerdts, V. (2015) Adjuvantien für veterinärimpfstoffe-Typen und workwise. Berl. Munch. Tierarztl. Wochenschr., 128(11-12): 456-463.

17. El-Sayed, M.H.N., El-Bagoury, G.F., El-Habbaa, A.S. and El-Makaky, H.M. (2018) Evaluation of combined inactivated vaccines against avian influenza subtypes $[\mathrm{H} 5 \mathrm{~N} 1$, H9N2] and avian infectious Bronchitis in chicken using montanide and paraffin oil adjuvants. Benha Vet. Med. J., 34(2): 121-139.

18. Mohammed, G., Shell, W.S., Sayed, M.S., Ibrahim, H. and El-Sadek, G. (2016) Efficacy of an experimental E. coli inactivated vaccine in turkey poults. J. Appl. Vet. Sci., 1(1): 7-14.

19. Salama, S.S., Abdelhady, H.A. and Atia, L. (2019) Field application for experimental inactivated multivalent $P$. multocida and avian influenza (H9N2) vaccine in poultry. Slov. Vet. Res., 56(22): 789-795.

20. Ghanem, H., ElEnbawy, M.P., Afifi, M., Soliman, I. and Khodier, L. (2015) Efficacy of montanide ISA-70-VG as adjuvant to fowl cholera vaccine. $J$. Vet. $A d v$., 5(3): 848.

21. Erganis, O., Hadimli, H. and Solmaz, H. (2002) Vaccine development from serotypes 01,02 and 078 of $E$. coli against avian colibacillosis: Layer chickens. Turk. J. Vet. Anim. Sci., 26(6): 1213-1221. 